\title{
Indonesia Hadapi Transisi “Oleng”: Perubahan Adalah Jawaban
}

\author{
Rizal Ramli \\ Rizal Ramli adalah tokoh oposisi nasional, mantan Menko Perekonomian dan kini memimpin Aliansi Rakyat \\ untuk Perubahan
}

\begin{abstract}
Changes always happen in this earth. Hence, this article wants to show how the nation needs a change. SBY-Boediono government is very weak and merely does not have firm sociological roots. Today government is like "Sand House" which is bound by image glue. Now, that image glue gradually melts after having given "deceit stamp" by some prominent religious figures, intelectuals, movement figures, workers, youths and students, and scandals involving the ruling party. Therefore, the fate of the Image Order will soon come to an end. The sand house will collapse, and it will not leave crucial problems, let alone ideological matters.
\end{abstract}

Kata Kunci: Indonesia; transisi; kerusakan hokum; ekonomi; politik

\section{Pendahuluan}

Indonesia terjerumus ke dalam transisi demokrasi yang oleng. Kini, sendi- sendi kehidupan bernegara di bawah pemerintahan SBY-Boediono semakin lama semakin lemah dan keropos. Kerusakan itu tercermin terutama di dalam bidang hukum dan ekonomi. Mafia hukum semakin merajalela, terutama karena tokoh-tokoh mafia hukum ternyata juga adalah para pejabat di kejaksaan, kepolisian dan lembaga peradilan. Akibatnya pisau hukum hanya tajam terhadap rakyat biasa, tetapi menjadi sangat tumpul terhadap kalangan elit yang memiliki uang dan kekuasaan.

Ekonomi nasional yang tumbuh sedang-sedang saja $(+6 \%)$ tidak mampu menciptakan lapangan pekerjaan, sehingga kesejahteraan rakyat semakin terpuruk. Sekitar kurang dari $20 \%$ penduduk yang paling atas memang hidup lumayan. Bisa menikmati arti kemerdekaan. Tetapi $80 \%$ sisanya belum pernah menikmati kemerdekaan.

Ketika pekerjaan nyaris tidak ada dan pendapatan mayoritas rakyat sangat rendah, kenaikan harga pangan dan harga kebutuhan pokok selama hampir setahun terakhir telah mengakibatkan kenaikan jumlah penduduk miskin $^{1}$ dan kemerosotan kehidupan. Kebijakan ekonomi neoliberal yang dijalankan oleh pemerintahan SBY-Boediono sudah terbukti di seluruh dunia tidak mampu meningkatkan kesejahteraan mayoritas rakyat, kecuali mening- katkan kemakmuran sebagian kecil elit di beberapa negara berkembang.

Yang lebih penting lagi kebijakan ekonomi neoliberal itu merupakan peng- khianatan terhadap konstitusi, seperti yang dirumuskan oleh para pendiri Republik Indonesia. Kemiskinan struktural, yang disebabkan oleh kebijakan ekonomi neoliberal, telah memicu peningkatan kejahatan, ladang subur kekerasan sosial, meningkatkan rasa putus asa dan tindakan bunuh diri. Kemiskinan juga memicu radikalisme, serta mempertajam konfik sosial dan agama.

Kerusakan dan kemerosotan yang terjadi di bidang hukum, kesejahteraan rakyat dan kehidupan sosial yang sedang terjadi sekarang ini, harus segera dihentikan. Kasus mafia pajak

\footnotetext{
${ }^{1}$ Standar kemiskinan pemerintah RI adalah Rp 211.726,oo/bulan atau Rp 7057,oo/hari (US\$ 0,78/ hari), atau hanya cukup untuk satu bungkus nasi dengan lauk sederhana. Tidak cukup untuk kehidupan yang manusiawi, apalagi jika diperhitungkan biaya perumahan, kesehatan dan pendidikan. Dengan standar yang sangat tidak manusiawi tersebut, jumlah orang miskin mencapai 31 juta orang (2010). Jika digunakan standar kemiskinan internasional yang US\$ 2/hari (Rp 18.000,oo/hari), maka jumlah penduduk miskin di negara kita akan naik tiga kali lipat angka kemiskinan versi pemerintah.
} 
Konfrontasi: Jurnal Kultur, Ekonomi dan Perubahan Sosial, 3 (1) Januari 2016, 46-52

P-ISSN: 1410-881X (Print)

Rizal Ramli: Indonesia Hadapi Transisi “Oleng": Perubahan Adalah Jawaban

DOI: -

http://www.konfrontasi.net/index.php/konfrontasi2

yang melibatkan pegawai pajak Gol III-A Gayus Tambunan yang berlarut-larut, tidak adanya tindakan terhadap "gayus-gayus" lain dan pejabat tinggi di Direktorat Jenderal Pajak serta Departemen Keuangan, merupakan contoh nyata dari lemahnya kepe- mimpinan nasional. Padahal berlarut-larutnya penanganan kasus mafia hukum dan mafia pajak akan memberikan kesempatan kepada calon-calon terdakwa untuk menghilangkan barang bukti.

Di bidang ekonomi, kebijakan yang dilakukan pemerintahan SBY-Boediono telah memperparah kondisi perekonomian nasional yang berdampak meningkatnya kemiskinan, pengangguran dan kian lebarnya kesenjangan ekonomi. Ketidakmampuan pemerintah melindungi hak-hak dasar warga negara, dalam bidang kesejahteraan dan agama, ${ }^{2}$ telah merusak tatanan kehidupan berbangsa dan bernegara.

Dengan kelemahan kepemimpinan SBY-Boediono, mengakibatkan berbagai masalah hukum, kesejahteraan rakyat, dan perlindungan hak-hak warga negara menjadi semakin parah. Lemahnya kepemimpinan nasional tersebut selain akibat karakter keduanya yang memang lemah, juga kenyataan bahwa sejak terpilih kembali dalam Pilpres 2009-2014 yang penuh kontroversi, SBY-Boediono telah menjadi bagian dari masalah, bukan bagian dari solusi.

Oleh sebab itu, ketika sejak hari pertama periode kedua kepemimpinan Susilo Bambang Yudhoyono sudah dibombardir oleh berbagai skandal (rekayasa bailout Bank Century, IT KPU dan DPT yang cacat berat), membuat rakyat semakin tidak memiliki harapan sehingga membahayakan kehidupan berbangsa dan bernegara. Penggunaan cara-cara Orde Baru (Orba), cara-cara militer yang brutal dan melanggar HAM di Papua, justru akan memperdalam luka dan perlawanan. Akan tetapi, membiarkan kelemahan kepe-mimpinan seperti ini, yang telah menimbulkan keme- rosotan, demoralisasi dan anomali di segala bidang, adalah tindakan yang tidak bertanggungjawab, sama dengan mem-biarkan Indonesia menjadi negara gagal karena mengabaikan tumbuhnya berbagai benih perpecahan di dalam tubuh NKRI.

Kita masih ingat Presiden Uni Sovyet Mikhail Gorbachev. Dia adalah pemimpin yang sangat santun, dipuji-puji oleh negara-negara Barat dan bahkan mendapat Hadiah Nobel dalam Bidang Perdamaian (1990). Tetapi kepemimpinannya yang sangat lemah membuat Uni Sovyet kacau dan berantakan. Perekonomian merosot tajam, tingkat pengangguran meningkat sangat tinggi, dan daya beli rakyatnya anjlok.

Kelemahan kepemimpinan Gorbachev itu terbukti menjadi salah satu penyebab utama runtuhnya negara adikuasa Uni Soviet (1991) yang kini tinggal tersisa hanya Rusia. Kita semua tidak ingin Indonesia semakin merosot dan mengalami disintegrasi seperti Uni Soviet. Kelemahan kepemimpinan dan ketidakmampuan SBY-Boediono mengemban amanat rakyat, melaksanakan konstitusi, harus dijadikan alasan utama untuk mem- percepat perubahan politik di negara yang kita cintai: Republik Indonesia.

Demokrasi memang merupakan jalan paling ideal untuk melahirkan perubahan. Tapi demokrasi yang bisa melahirkan perubahan dan bermanfaat untuk rakyat adalah demokrasi yang baik dan benar. Sedangkan model demokrasi yang saat ini berlangsung di negara kita adalah "demokrasi kriminal", demokrasi yang telah dibajak oleh kekuatan uang dan oligarki, sehingga tidak akan memberi manfaat untuk mayoritas rakyat. Demokrasi kriminal hanya meningkatkan kesejahteraan para pejabat negara, baik di eksekutif legislatif maupun yudikatif.

Anggaran belanja pegawai meningkat hampir empat kali dari Rp. 54 triliun tahun 2005 menjadi Rp 181 triliun pada 2011. Biaya perjalanan untuk pejabat pemerintah dan DPR mencapai Rp 19,5 trilliun4 atau 4 kali lebih besar dari Jaminan Nasional Kesehatan pada

\footnotetext{
${ }^{2}$ Kasus kekerasan agama di Cikeusik, Pandeglang, Banten (6/2/2011) dan Temanggung, Jawa Tengah (9/2/2011).
} 
Konfrontasi: Jurnal Kultur, Ekonomi dan Perubahan Sosial, 3 (1) Januari 2016, 46-52

P-ISSN: 1410-881X (Print)

Rizal Ramli: Indonesia Hadapi Transisi “Oleng": Perubahan Adalah Jawaban

DOI: -

http://www.konfrontasi.net/index.php/konfrontasi2

APBN 2010. Dengan pem- borosan seperti itu, pemerintah SBY-Boediono mengaku tidak memiliki uang untuk menyelenggarakan Sistem Jaminan Sosial Nasional5 yang akan memberikan jaminan kesehatan dan pengangguran untuk pekerja.

Dengan kenaikan belanja pegawai yang sangat besar tersebut, birokrasi justru semakin korup dan semakin tidak bertanggungjawab. Program remunerasi yang digembar-gemborkan akan berdampak meningkatkan kinerja birokrasi, tidak lain dan tidak bukan hanya sekedar program kenaikan gaji tanpa diikuti oleh kenaikan kinerja maupun akuntabilitas jajaran birokrasi kita. Proses birokratisasi sengaja dibikin berbelit-belit supaya rakyat dan pengusaha bisa diperas, dan agar sistem pertanggung- jawaban semakin tidak jelas.

Indonesia tidak mungkin menjadi negara besar dengan rakyat hidup makmur tanpa adanya reformasi birokrasi secara total. Sebab dalam prakteknya, birokrasi lebih sering menjadi bagian dari masalah, dan bukan solusi.

Demokrasi kriminal juga memungkinkan terjadinya pembiaran kejahatan pemilu berlangsung dari hulu sampai hilir, dari PPS sampai KPU Pusat. Berbeda dengan Pemilu-pemilu sebelumnya, pada pemilu lalu tidak ada satu pun kasus Pemilu signifkan yang diproses oleh Kepolisian Republik Indonesia. Kebijakan itu sengaja dirancang oleh kekuasaan dan kepolisian. Hukum dan ekonomi dirancang untuk saling melindungi kepentingan elit politik. Kepemimpinan SBY-Boediono yang lemah semakin mendorong berkembangnya demokrasi kriminal sehingga terjadi politik saling menyandera di kalangan elit politik.

Dalam konteks demokrasi kriminal dan kelemahan kepemimpinan yang fatal, perubahan politik harus dilakukan sekarang juga untuk mencegah kerusakan dan kemerosotan yang lebih parah lagi. Perubahan adalah solusi dari perangkap demokrasi kriminal, pemerintahan lemah dan bermasalah. Perubahan politik itu merupakan upaya untuk membuat demokrasi sungguhsungguh bekerja untuk kepentingan rakyat, bukan demokrasi kriminal yang hanya menguntungkan kepentingan sekelompok kecil elit.

Oleh karena itu perubahan politik harus dilakukan segera. Proses perubahan politik tersebut bukanlah upaya kudeta ataupun makar, karena perubahan yang dilakukan sepenuhnya diharapkan dan didukung oleh kekuatan sipil dengan cara-cara damai, tanpa kekerasan dan tetap berlandaskan substansi demokrasi. Makar dan kudeta hanya dapat dilakukan oleh kekuatan bersenjata atau militer dengan cara kekerasan bersenjata. Pemerintaham SBY-Boediono, lewat menteri-menterinya, sering melontarkan istilah "makar dan kudeta" untuk menakut-nakuti kekuatan rakyat demokratis.

\section{Untuk Apa Perubahan?}

Perubahan harus segera dilakukan untuk menghentikan demokrasi kriminal dan membuat demokrasi betul-betul bekerja untuk kepentingan rakyat. Perubahan juga diperlukan untuk mengubah kepemimpinan nasional yang lemah dan bermasalah dengan kepemimpinan nasional yang efektif7 dan sungguh-sungguh menegakkan konstitusi, baik dalam bidang politik, hukum, ekonomi maupun sosial.

Penegakkan hukum akan dilakukan tanpa tebang pilih, sehingga setiap warganegara akan diperlakukan sama di hadapan undang-undang. Agar sistem demokrasi sungguhsungguh bekerja untuk kepentingan rakyat, dan tidak dibajak oleh kekuatan uang, maka perlu dilakukan reformasi pembiayaan partai politik. Seperti halnya di Jerman dan Australia, partai- partai politik akan dibiayai oleh APBN dengan perkiraaan biaya maksimum Rp 0,5 triliun/tahun. Angka tersebut sangat kecil dibandingkan dengan total APBN yang 
Konfrontasi: Jurnal Kultur, Ekonomi dan Perubahan Sosial, 3 (1) Januari 2016, 46-52

P-ISSN: 1410-881X (Print)

Rizal Ramli: Indonesia Hadapi Transisi “Oleng": Perubahan Adalah Jawaban

DOI: -

http://www.konfrontasi.net/index.php/konfrontasi2

mencapai Rp 1.200 triliun, dan dibandingkan dengan kerugian dan kerusakan yang ditimbulkan akibat sistem demokrasi kriminal.

Sebagai prasyarat untuk mendapatkan biaya tersebut, partai-partai politik harus bersedia diaudit (termasuk audit investigatif), turut serta menciptakan clean government dan good governance, dengan cara hanya boleh meng- ajukan calon legislatif dan eksekutif yang memiliki integritas, kepemimpinan dan track record yang baik. Integritas, kepemimpinan dan track record harus menjadi kriteria utama kaderisasi di partai-partai politik.

Perubahan juga akan dilakukan dalam bidang ekonomi. Kebijakan ekonomi neoliberal yang sudah berjalan lebih dari 40 tahun, yang tidak berpihak kepada rakyat dan kepentingan nasional, akan digantikan dengan sistem ekonomi berbasis konstitusi UUD 1945, yaitu sistem ekonomi yang lebih berpihak kepada rakyat (ekonomi domestik) dan kepentingan nasional.

Prioritas utama akan diarahkan untuk menciptakan kemandirian dalam bidang pangan, penciptaan lapangan kerja, peningkatan kesejahteraan rakyat (melalui pengembangan karakter dan pendidikan), pembangunan infrastruktur, maksimalisasi nilai tambah di sektor pertanian, perikanan, peternakan, industri, pertambangan dan sumberdaya alam lainnya.

Sumber daya alam akan dikelola dan dimanfaatkan sebesar-besarnya untuk peningkatan kesejahteraan rakyat. Negara akan memainkan peranan yang proaktif untuk mempercepat pembangunan ekonomi dan peningkatan kesejahteraan rakyat. Percepatan tersebut juga dimaksudkan agar Indonesia dapat segera mengejar ketinggalannya dari negara-negara tetangga seperti Singapura, Malaysia dan Thailand. Dengan sumber daya alam yang luar biasa, penduduk yang besar dan posisi geografs yang sangat strategis, Indonesia akan bisa menjadi salah satu negara besar yang sejahtera dan kuat di kawasan Asia.

Peranan pemerintah yang proaktif untuk mempercepat pembangunan ekonomi dan meningkatkan kesejahteraan hanya mungkin dilakukan jika diikuti dengan reformasi birokrasi total, termasuk di antaranya penye- derhanaan proses birokratif, sistem rekruitmen dan promosi yang kom- petitif, sistem insentif berdasarkan kinerja, penegakkan transparansi dan akuntabilitas. Jika reformasi total tersebut dilakukan, peng-hematan anggaran dapat mencapai 30 persen dan penerimaan negara bisa naik sampai 30 persen. Sehingga tersedia dalam jumlah yang cukup anggaran untuk program-program peningkatan kesejahteraan rakyat.

\section{Faktor-faktor Obyektif Pendukung Perubahan}

Sejarah menunjukan bahwa perubahan politik di banyak negara di seluruh dunia, hanya dapat terjadi jika didukung oleh faktor-faktor obyektif dan subyektif. Kondisi saat ini menunjukan bahwa secara obyektif, kondisi Indonesia sudah matang untuk perubahan seperti ditunjukkan oleh hal sebagai berikut ini:

1. Mayoritas kalangan intelektual tidak lagi yang bersedia membela pemerintahan SBYBoediono secara terbuka, kecuali intelektual yang sudah dikontrak Istana. Padahal di negara demokratis, kalangan intelektual sangat menentukan legitimasi kekuasaan. KKN (korupsi, kolusi dan nepotisme), yang harus diberantas sesuai amanat utama reformasi 1998, justru semakin menggurita pada masa pemerintahan SBY-Boe- diono ini. Bahkan dalam soal nepotisme, pemerintahan sekarang dengan cepat mengalahkan "prestasi" yang pernah dilakukan rezim Soeharto.

2. Media, terutama media berjaringan internet dan media elektronik (TV dan Radio) sangat kritis dan juga skeptis terhadap ketulusan dan kinerja pemerintahan SBY-Boediono. Partisipasi publik dalam bidang sosial dan politik semakin tinggi seiring dengan 


\section{Rizal Ramli: Indonesia Hadapi Transisi “Oleng": Perubahan Adalah Jawaban}

DOI: -

http://www.konfrontasi.net/index.php/konfrontasi2

meluasnya penggunaan jejaring sosial (facebook, twitter) radio dan TV, yang bisa dikendalikan dari perangkat komunikasi genggam yang mobil dan makin canggih.

3. Para aktivis pro-demokrasi, pemuda dan mahasiswa di seluruh Indonesia telah sepakat menilai bahwa pemerintahan SBY-Boediono "gagal" karena tidak berpihak kepada kepentingan mayoritas rakyat, dan hanya patuh pada kepentingan global dan pemodal besar/asing. Selama satu tahun terakhir setiap kunjungan SBY-Boediono ke seluruh wilayah Indonesia selalu diikuti dengan demonstrasi mahasiswa dan pemuda yang menentang kehadiran mereka.

4. Banyak tokoh politik senior Indonesia, juga para pejuang kemerdekaan dan jenderal purnawirawan TNI menganggap penggantian SBY-Boediono harus segera. Lebih cepat lebih baik, demi kepentingan nasional terutama karena alasan kepemimpinan dan karakter yang sangat lemah.

5. Para tokoh agama terkemuka menyatakan bahwa pemerintahan SBY- Boediono telah melakukan banyak kebohongan dan mengingkari konsti- tusi.9 Ketika rakyat membutuhkan, terutama dalam hal kenyamanan beragama dan kesejahteraan, pemerintahan SBY-Boediono sering absen, tidak hadir. Rakyat dibiarkan mengatasi berbagai persoalannya sendiri.

6. Kehidupan mayoritas rakyat Indonesia, yang berpendapatan sangat rendah dan banyak yang menganggur10, semakin sulit karena kenaikan harga pangan dan kebutuhan pokok yang tidak terkendali. Selain karena sifat rezim yang otoriter, perubahan politik di Indonesia (1966 dan 1998), Tunisia dan Mesir (2011) terjadi terutama karena pengangguran yang sangat tinggi dan kesulitan pangan yang dihadapi mayoritas rakyat.

7. Selain gangguan terhadap kenyamanan kehidupan beragama, ada juga gangguan terhadap hak-hak historis sebagaimana dirasakan masyarakat di Yogyakarta11 sehingga memicu ketidakpuasan, dan menunjukan ketidakmampuan pemerintahan SBY-Boediono meneruskan cita-cita para founding father dan melaksanakan amanat kon-stitusi.

8. Liberalisasi di bidang pendidikan nyaris identik dengan kenaikan biaya pendidikan yang resmi maupun tidak resmi, baik di lembaga pendidikan swasta maupun milik negara. Akses terhadap pendidikan untuk rakyat miskin semakin terbatas, dan tingkat putus sekolah di berbagai jenjang pendidikan semakin tinggi. Walaupun ada wajib belajar 6 tahun, tingkat putus Sekolah Dasar mencapai 1,7 persen terutama karena kesulitan ekonomi. Walaupun ada wajib belajar 9 tahun dan alokasi anggaran pendidikan dinaikkan, ternyata dari 26 juta anak usia sekolah 7 - 12 tahun, 4,89 juta anak atau 18,4 persen terbukti tidak dapat melanjutkan pendidikan ke jenjang menengah.

9. Pemerintahan sekarang telah mengalami krisis kepercayaan (distrust) publik, sama ketika menjelang kejatuhan Presiden Soeharto. Krisis kepercayaan timbul karena rakyat menyaksikan perbedaan yang sangat besar antara perkataan (janji) dan tindakan (kenyataan) pemerintah SBY-Boediono. Atau mengutip seloroh Buya Syaf'i Ma'arif, "pecah kongsi antara perkataan dengan realitas!" Paling mencolok tentu saja maraknya praktek rekayasa (metodologi) statistik dan kinerja. Sehingga secara umum, publik menilai pemerintah SBY-Boediono telah menjadi bagian dari masalah, bukan solusi.

\section{Alasan Konstitusional}

Pemimpin yang mengingkari konstitusi karena ketidakmampuannya dalam menegakkan prinsip negara hukum, tidak mengambil tindakan terhadap berbagai kejahatan kerah putih seperti skandal rekayasa bailout Bank Century12, mafa hukum dan skandal 
Konfrontasi: Jurnal Kultur, Ekonomi dan Perubahan Sosial, 3 (1) Januari 2016, 46-52

P-ISSN: 1410-881X (Print)

Rizal Ramli: Indonesia Hadapi Transisi “Oleng": Perubahan Adalah Jawaban

DOI: -

http://www.konfrontasi.net/index.php/konfrontasi2

restitusi pajak, menjalankan kebijakan ekonomi neoliberal yang bertentangan dengan konstitusi, dan tidak mampu menjamin hak-hak dasar warga negara dalam bidang kesejahteraan dan kenyamanan beragama sudah waktunya mengakhiri masa jabatannya. Krisis kepercayaan yang semakin meluas, kesulitan hidup rakyat yang semakin berat dan pembiaran berkembangnya demokrasi kriminal merupakan faktor-faktor pendukung percepatan perubahan.

\section{Proses Perubahan}

Indonesia merupakan negara pertama yang merdeka setelah berakhirnya Perang Dunia II pada 1945. Setelah Indonesia merdeka barulah negara- negara Asia Pasifk dan Afrika lainnya menyatakan kemerdekaannya, seperti India (1947), China (1949), Mesir (1953), Sudan (1956), Aljazair (1962), dll.

Dengan semangat kemerdekaan dan nasionalisme yang kuat, Indonesia menjadi salah satu pioner konferensi Asia Afrika di Bandung tahun 1955, yang memberikan inspirasi dan mendorong negara-negara berkembang lainnya untuk segera menyatakan kemerdekaannya dari kolonialisme.

Pada 1998, Indonesia juga memberikan contoh kepada dunia bagaimana melakukan transisi dari rezim otoriter menjadi negara demokratis. Proses transisi seperti dilakukan bangsa Indonesia pada 1998 kini sedang berlangsung di Tunisia, Mesir dan Yaman, dan beberapa negara di kawasan Timur Tengah lainnya. Dalam perubahan politik, Indonesia memang tidak pernah mengimpor pengalaman dari negara lain, tetapi justru sebaliknya, menjadi pionir dan menjadi contoh bagi negara-negara lainnya.

Sekarang Indonesia kembali menunjukan kepada dunia bahwa demokrasi prosedural dan kriminal, yang banyak terjadi di sejumlah negara berkembang, ternyata gagal mening-katkan kesejahteraan rakyat dan gagal membawa kejayaan dan kemakmuran bagi bangsanya. Dalam konteks ini, Indonesia harus kembali memberikan contoh bagaimana mengubah "demokrasi prosedural yang cenderung kriminal" menjadi sistem demokrasi yang sungguh-sungguh bekerja untuk meningkatkan kesejahteraan rakyat, sehingga Indonesia menjadi salah satu negara besar di Asia.

Beberapa negara di Asia memang ada yang berhasil mencapai tujuan (kesejahteraan) tersebut melalui sistem dan cara-cara yang tidak demokratis. Tapi itu bukan jalan yang dicitacitakan para founding father kita. Oleh sebab itu, jika kita berhasil melakukan perubahan demokrasi kearah yang lebih baik tersebut terjadi, maka Indonesia kembali akan memberikan contoh kepada Negara-negara Dunia Ketiga bahwa demokrasi ternyata mampu meningkatkan kesejahteraan (rakyat) dan kejayaan bangsa Indonesia.

\section{Kesimpulan}

Perubahan politik dari otoriter ke demokratis di Indonesia pada 1998 dan di Mesir sekarang ini relatif sulit dan alot karena Presiden Soeharto dan Presiden Mubarak telah berkuasa lebih dari 30 tahun, didukung sepenuhnya oleh militer, jaringan intelijen dan partai berkuasa yang telah menggurita. Jika dibandingkan dengan Presiden Soeharto maupun Presiden Mubarak, Pemerintahan SBY-Boediono sangat lemah dan sama sekali tidak memiliki akar sosiologis yang kuat.

Pemerintahan saat ini bagaikan "Rumah Pasir" yang direkat oleh lem pencitraan. Sekarang lem pencitraan itu telah meleleh setelah diberi "cap kebohongan" oleh para pemuka agama, kalangan intelektual, tokoh pergerakan, kaum buruh/pekerja, pemuda dan mahasiswa. 
Konfrontasi: Jurnal Kultur, Ekonomi dan Perubahan Sosial, 3 (1) Januari 2016, 46-52

P-ISSN: 1410-881X (Print)

Rizal Ramli: Indonesia Hadapi Transisi “Oleng": Perubahan Adalah Jawaban

DOI: -

http://www.konfrontasi.net/index.php/konfrontasi2

Dengandemikian, akhir dari Orde Citra tinggal menunggu waktu. Rumah pasir itu akan roboh dengan sendirinya. Dan tidak akan meninggalkan persoalan krusial, apalagi ideologis.

Di atas reruntuhan rumah pasir itulah kita bangun rumah Indonesia yang kokoh, dengan fondasi konstitusi yang kuat, sehingga membuat seluruh penghuninya merasa nyaman, sehat, punya pekerjaan, sehingga mampu menyekolahkan anak-anaknya. Jika sakit akan sanggup berobat ke dokter atau rumah sakit. Hanya dengan cara demikian bangsa Indonesia akan dihormati oleh bangsa-bangsa lain di dunia.

\section{Bibliografi}

Castles Lance. Feith Herbert (ed) 1988. Pemikiran politik Indonesia 1945-1965 Jakarta : LP3ES

Daniel Dhakidae, 2003, Cendekiawan dan Kekuasaan dalam Negara Orde Baru,Jakarta: Gramedia Pustaka Utama.

Easter, David. 2005. "Keep the Indonesian Pot Boiling: Western Intervention in Indonesia, October 1965-March 1966" dalam Cold War History, Volume 5, Number 1, February.

Maswadi Rauf, 2006, Partai Politik dalam Sistem Kepartaian di Indonesia Antara Kenyataan dan Harapan. Akbar Tandjung Institute. Jurnal Politik. Vol. 2. No. 2.

Moh. Mahfud M.D, 2001, Dasar Dan Struktur Ketatanegaraan Indonesia. Edisi Revisi. Jakarta; Rineka Cipta.

Muchamad Ali Safaat, 2009, Pembubaran Partai Politik di Indonesia, Disertai UI, Jakarta. 